\title{
Research of the Elderly Pension Situation Based on Methods of Social Survey \\ Ying DENG ${ }^{1, a}$, Qi-Bo Al, ${ }^{1, b}$ \\ ${ }^{1}$ School of Business Administration, Hohai University, Changzhou 213002, China

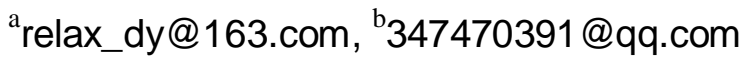

Keywords: Elderly pension, Nursing institution, Endowment insurance, Health care, Survey

\begin{abstract}
Along with the decline of the natural population growth rate, the improvement of economic level and medical developments in our country, the average population life expectation is gradually extended. Thus aging problem has caused widespread attention. This paper mainly summarized the problems such as aging trend, the pension institutions, community pension, raising pension funds and so on. And put forward improvement suggestions about improving the pension and health care systems, supporting pension institutions, developing the aging pension services, creating an atmosphere of respecting the aged.
\end{abstract}

\section{Introduction}

Aggravation of the aging population has not only brought about many social problems in seeing doctors, support and social burden etc, but also caused the elderly many psychological problems. In that case, this paper collected the views of relative government departments, pension institutions and the sampling survey results of some communities. Then it summarizes the common needs and problems of the elderly, and finally puts forward some improvement measures which are aimed at attracting the attention of societies and providing some ideas for the aging business.

The object of study is the old people over the age of 60 who were living in the city from June 2013 to September 2014. We took the methods of questionnaire investigation, point investigation and visiting survey in the research and visited two official institutions, three nursing institutions and four old communities.

\section{Research content}

\section{Aging trend}

The city became an aging city in 1985. It contained $14.06 \%$ of old people over the age of 65 until the end of 2012, which had rose by $4.28 \%$ than 2010 . The result is far higher than the society aging standard. The trend of aging is mainly reflected in the following aspects:

The aging process is faster. The aging of the population has increased in recent years, and the proportion of household registration number was continued growing. Data are as Fig.1.

The number of oldest old is increasing. There were 114.5 thousand old people aged above 80 until 2012, which had increased by 3.1 thousand people than 2011 .

As shown in the Fig.2, the average life expectancy is gradually rising from the results of third census to the sixth one. We can find that the average life expectancy is close to the age of 80 , which means that heavier social supporting burden and fewer personal resources, which must be an obstructive factor in society development. 


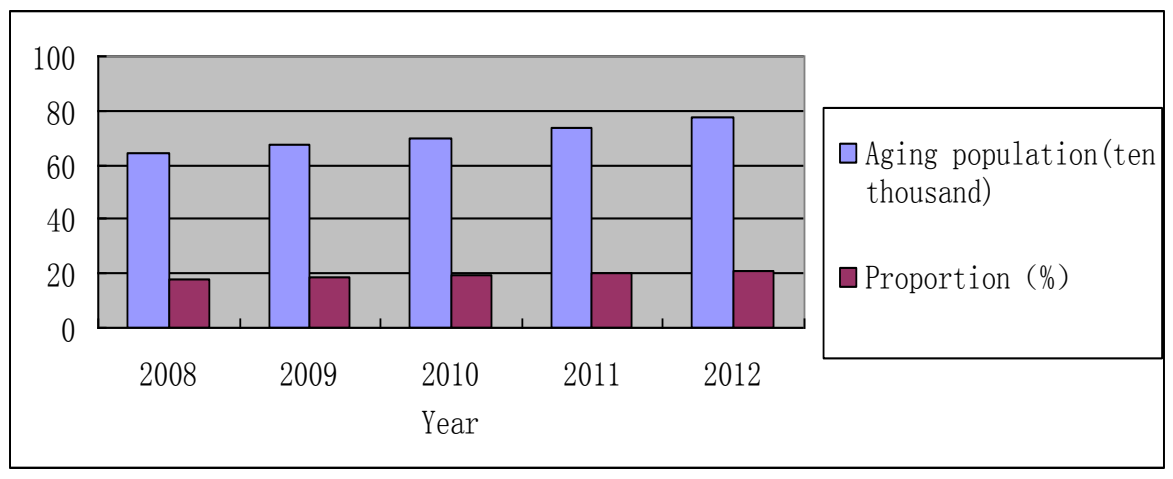

Figure 1 The number and the proportion of elderly

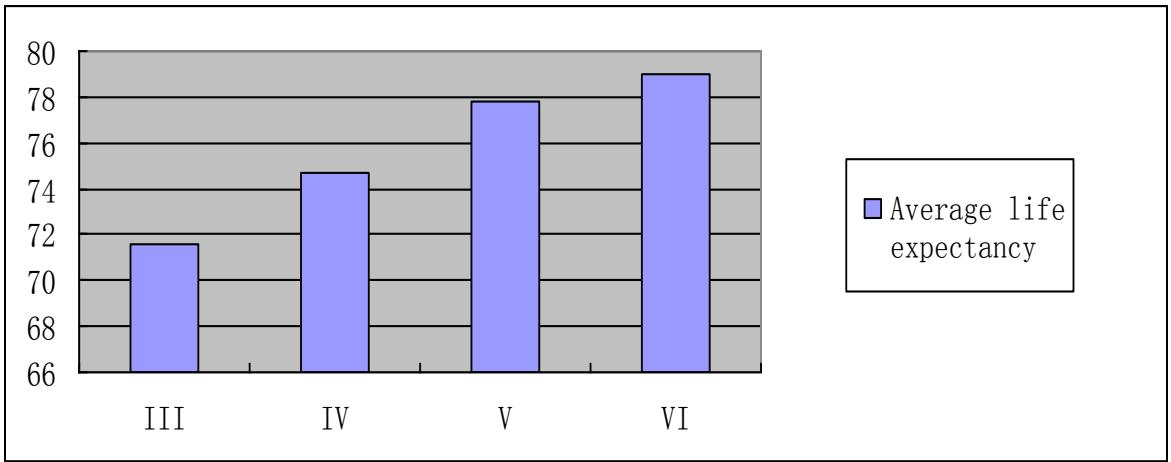

Figure 2 Average life expectancy in the city from the third to sixth census

\section{The status quo of nursing institutions}

There are totally 95 nursing institutions in the city. The following table 1 is about the distribution of nursing institutions and aging population

Table 1 Distribution of pension institutions and aging population

\begin{tabular}{cccccc}
\hline Region & Institutions & Beds & Aging population & Age above 80 & $\begin{array}{c}\text { Distribution } \\
\text { density }\end{array}$ \\
\hline Region 1 & 15 & 2310 & 120216 & 19494 & 0.118 \\
Region 2 & 13 & 3146 & 164290 & 28565 & 0.110 \\
Region 3 & 24 & 4173 & 229801 & 30877 & 0.135 \\
Region 4 & 13 & 3407 & 85646 & 10536 & 0.323 \\
Region 5 & 19 & 2562 & 78191 & 11646 & 0.220 \\
Region 6 & 10 & 1029 & 75043 & 10478 & 0.098 \\
Region 7 & 1 & 241 & 18961 & 2910 & 0.083 \\
Total: & 95 & 16868 & 772148 & 114506 & 0.147 \\
\hline
\end{tabular}

Instead of low distribution density in region 1 , the per capita number of beds is nearly 0.1 , the result is below the national level. So it is necessary for government to support the establishment of private institutions. Our group investigated three pension institutions. The following conclusions can be drawn after the interview.

\section{Factors of nursing institution}

(1) Health care. Every nursing institution has cooperated with medical institutions or has its own health station. And some of them are even equipped with professional psychologists who can surely cope with emergencies. There are regular physical examinations for the aged in state-running retirement organizations, while the private ones do not have, unless aged people feel uncomfortable. That phenomenon results from the lack of money. 
(2) Favorable conditions. The organizations we have visited all have the well-equipped facilities and good environment. As for other retirement organizations in the city, the facilities of personal ones could be probably not as good but they will not influence the healthcare quality highly.

(3) Weak nursing workers team. Their work is featured dirty, fatigue, lower social status, and low salary. Because of the poor wage, few people would like to choose this job. There are not too much training, except state-running institutions processing formal regular trainings and qualification check.

(4) Low occupancy rate. The three institutions we have visited are all not full, particularly, one of them not arrived at 50\%. Low occupancy rate makes the institutions running hare. Many old people do not want to leave from family. High expense is another reason.

\section{The factors of old people}

(1) Living in nursing institutions is most appropriate. Nowadays, young people are busy of working with little time to take care of their aged parents, even when their parents are sick. On the other hand, some old people have problems with families, the pension institutions must be the best choice. They will be taken good care of from sleeping, eating to leisure time in the institutions.

(2) Missing families. The elders have a lot of vacant time. The sense of loneliness is strong. But normally, their families is seldom come to see them.

(3) Psychological problems. Psychological problems are very common. There are many reasons such as missing relatives, family conflicts and individual mental factors. Mental state will greatly affect the quality of life, so it is important to let them have an optimistic altitude to face life.

\section{The present situation of community endowment}

To learn the endowment situation of the majority of the aging population more directly, our group has visited 4 communities which were established for a long time in the city. Most of the residents in these four communities are enterprise employees and their families. The rest are some migrant workers and scattered tenants.

\section{Financial Capacity}

(1) Consumption level. According to the investigation on the random examples of 25 families from the communities, we found that the consumption level of the old people is irregular, for their monthly expenses range from less than $¥ 500$ to over $¥ 2000$. However, there is a certain relationship between age difference and consumption capacity.

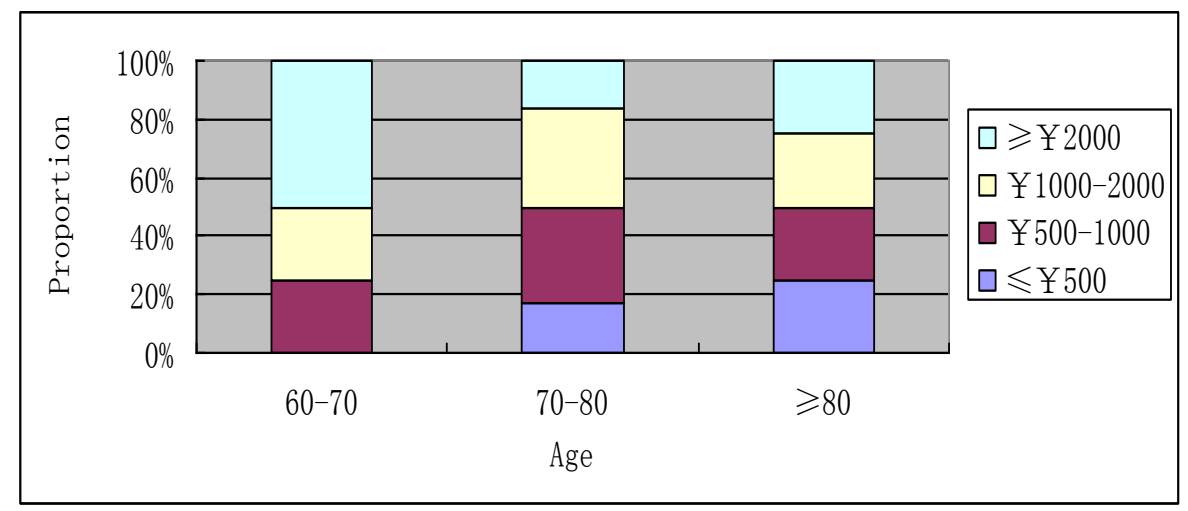

Figure 3 Consumption capacity of different ages

As is shown in Fig.3, the older these people are, the lower their consumption level tends to be. Monthly expense of most old people aging from 60 to 70 are over $¥ 2000$. It means that along with the age increasing, the consumption activities will be much less than before and the consumption attitude of them will be changed a lot. That will explain why the old people will feel much lonelier and get bored with their life as their age increasing.

(2) Income Resource. Most the aged we investigated have reliable financial resources. We can learn the details shown in Fig.4. 


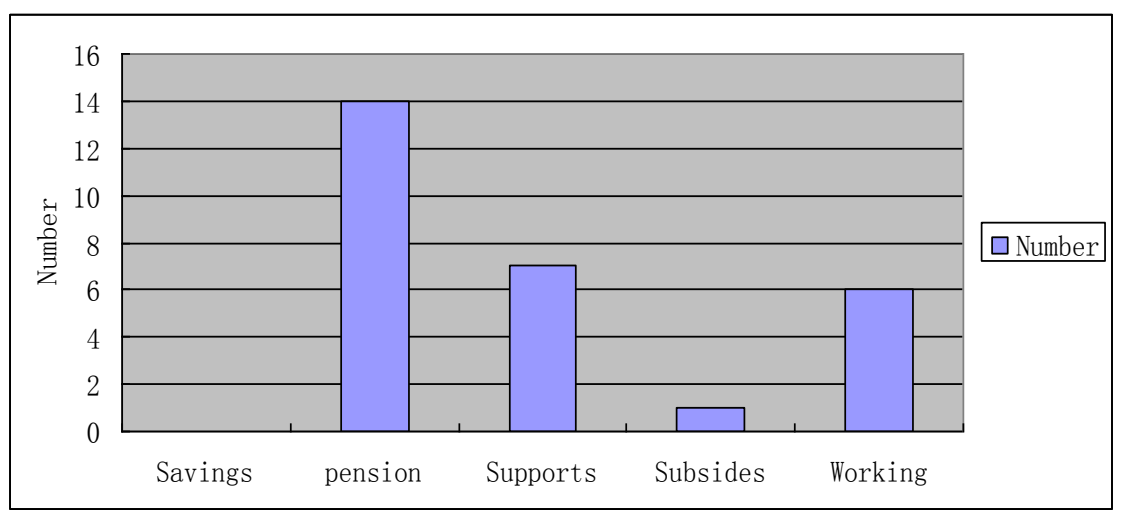

Figure 4 The number of various sources of income

In conclusion, pension accounts for the highest proportion. Among these three financial resources, the retirement pension accounts for the largest proportion. Usually, these old people who can receive pension are able to support their daily expenses themselves. However, working to ensure a basic life expense is still very common nowadays.

\section{Families}

According to the survey, there are only $64.3 \%$ aged are willing to live with their children in three or four generations families, mainly due to problems which are resulted from too many families. Also, we can learn that the old people tend to communicate with their children, spouse or neighbor.

\section{Elderly pension recognition}

(1) Choosing a kind of endowment pattern. From the whole society's view, they have a variety of opinions about Endowment patterns, and most of them put the idea of being looked after by children on the first place.

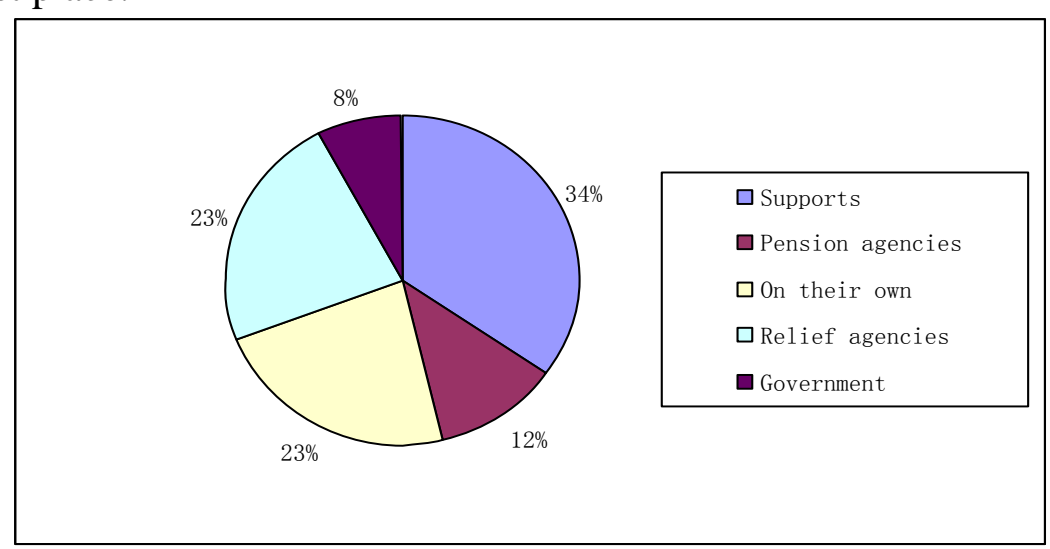

Figure 5 Endowment patterns and its proportion

As can be seen from the Fig. 5 result from 25 families interviewed, few people think that they should be taken care of by government, that's to say, their children and social relief agencies should look after them.

(2) Satisfaction of old-age security. From Fig.6, we can find out the old men who are in bad condition often hold the opinion that the national protection's rule is not considerate, but people who are in normal condition are satisfied with the current situation. Also, old people who feel satisfied with their condition account for the most parts. 


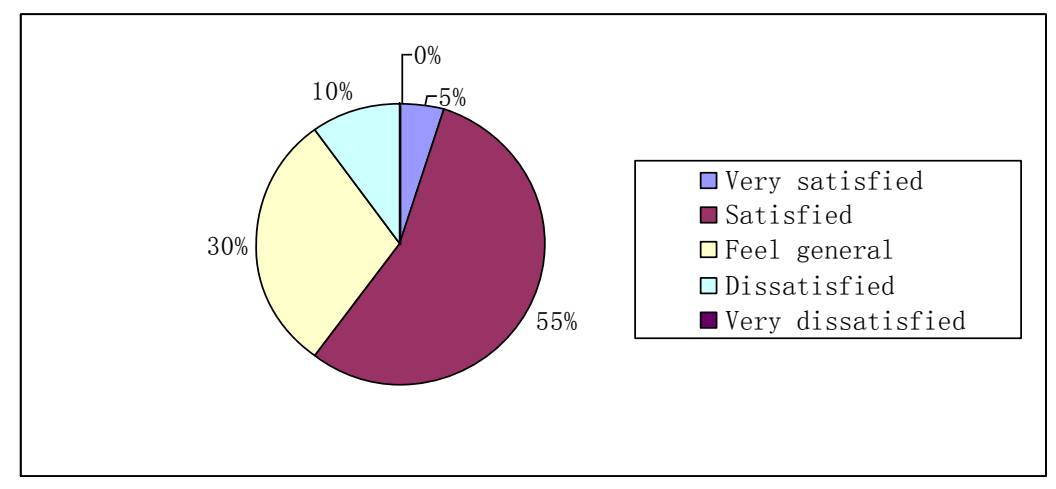

Figure 6 Satisfaction of old-age security

(3) The responsibility for aging passion. With the development of society, from 1985 to 2005, the government's slogan have also become changed from the idea that government has responsibility to the opinion that providing for the aged can not depend on government. What's more, these unrealized promises make people angry. From the survey, $70 \%$ of old people think that the government absolutely have obligation to shoulder the work for them, and others think this responsibility should be taken over by their children.

\section{Improvement measures}

\section{Improve the pension system}

Pension is the direct reflection of the pension situation. The government should start from pensions such as reducing the pension gap of between administrative departments and enterprises, and gradually improving the "double track", according to the contribution to set up pension amount. Improve the level of urban residents of retirement at the same time with the more vulnerable elderly subsidy.

Consideration should be given to investment on the other hand, applying a system of "universal pension", namely, every citizen should be enforced to join the pension system in their youth.

\section{Improve the endowment institutions system}

At present most endowment institutions in our country are community welfare institutions. In order to face more diversified demand in the future, the government ought to set up more institutions which can provide health care, education, social communication and recuperate. The government should also force endowment in accident injury insurance organizations. The government should also encourage foreign enterprise to set up them and enjoy equal policy treatment with local ones.

On the other hand, if we let the urban old people generally take community endowment patterns, willing having a high efficiency of pension. First of all, the community endowment can have a deeper sense of identity belonging. Second, the old are more familiar with community endowment environment, more convenient for family members; Moreover, collective pension mode more effectively using and integrating the endowment resources. Government can start to establish separated community endowment department, being responsible for the elderly community endowment activity, taking shape of pension mode so that we can solve the urban pension problem in a wide range.

\section{Improve the elderly health care system}

There is rarely a geriatric hospital around the country. It is difficult and expensive for the elderly to see a doctor. The pension of many retired workers is not enough to support the cost of seeing a doctor. Therefore, it is necessary to set up welfare hospitals equipped with professional care-staff and establish the visit-care system. In this way, the hospital can meet the various needs of the 
elderly.

\section{Encourage the development of the elderly services}

There is no specialized research team for elderly service in our nation. In most cases, the solutions to problems in pension endowment often cause a fierce social controversy. Because of the high expense of nursing institutions, many old people can not take this way. To solve these difficulties we must establish more institutions of nursing personnel training, appeal to attention for elderly nursing and encourage society to establish nursing institution. Besides, with the increasing demand for elderly services, colleges and universities also have an obligation to cultivate highly qualified talents, who can work in nursing institutions.

\section{Strengthen the construction of social morality}

Social attention can speed up the pension process and the social values about pension will greatly affect the elderly population. The government should set up the fashion that respecting elders. Social pension management institutions for the elderly should do more practical work and useful thing; On the other hand, praising the people who respect the old and criticizing who has the wrong behavior is necessary. Thus a harmonious society will be established.

\section{Acknowledgment}

The paper is the research achievement of the National Undergraduate Innovative Training Project "The Pension Situation Investigation of the Aging Population in Changzhou City" (20131029407).

\section{Reference}

[1] Jiang-bin Li. Extraction of strategy for the ageing of Heilongjiang province, J. Journal of Statistics and Consulting, 2012, (2).

[2] Information on http://www. changzhou. gov. cn/ns_news / 931134311069550.

[3] Ya-qing Liu. The study about spiritual life of the elderly, J. Journal of Theory, 2014, (1).

[4] San-jun Fang. Investigation and thought about the situation of rural elderly endowment in more developed areas - taking D city in Zhejiang province countryside for example, J. Journal of Law and Society, 2011, (36).

[5] Rui-ying Shen. Analyses in China's urban pension mode - home based care for the aged, J. Forward Position, 2009, (1).

[6] Zhao Jing, Ding-fu Jiang, Jian-xiong Ma. New exploration of Endowment pattern: networked home endowment, J. Journal of Cooperation in Economy and Technology, 2014, (4).

[7] Wang Wei. The countermeasure research about effects of an ageing population for the Japanese economy and the Japanese government, D. The Dongbei University of Finance and Economics, 2007. 